Pacific Journal of Mathematics

HARNACK'S INEQUALITIES ON THE CLASSICAL TARTAN
DOMAINS 


\title{
HARNACK'S INEQUALITIES ON THE CLASSICAL CARTAN DOMAINS
}

\author{
SHIH-HSIUNG TUNG
}

\begin{abstract}
Recently an extensive work by L. K. Hua on harmonic analysis in Cartan domains, which are called the classical domains, has been translated into English. Here we give Harnack's inequalities for the four main types of Cartan domains treated by Hua.
\end{abstract}

Harnack's inequality on a type of Cartan domain was obtained [6] for the case of square matrix spaces. Some of these inequalities are application and extension of the results of [6]. I am grateful to Professor J. Mitchell for her encouragement and comments on writing this paper.

Let $z$ be a matrix of complex entries, $z^{*}=\bar{z}^{\prime}$ the complex conjugate of the transposed matrix $z^{\prime}$ and $I$ the identity matrix. Also $H>0$ means that a hermitian matrix $H$ is positive definite. The first three types of Cartan domains are defined by $D_{k}=\left\{z: I-z z^{*}>0\right\}$, $k=1,2,3$, where for $D_{1} \equiv D_{1}(m, n), z$ is an $(m, n)$ matrix (Since the conditions $I-z z^{*}>0$ and $I-z^{*} z>0$ are equivalent we assume for definiteness that $m \leqq n$.), for $D_{2} \equiv D_{2}(n), z$ is a symmetric matrix of order $n$ and for $D_{3} \equiv D_{3}(n), z$ is a skew-symmetric matrix of order $n$. The fourth type, $D_{4} \equiv D_{4}(1, n)$, is the set of all $(1, n)$ matrices, or $n$-dimensional vectors $(n>2)$, of complex numbers satisfying the conditions

$$
1+\left|z z^{\prime}\right|^{2}-2 z z^{*}>0, \quad\left|z z^{\prime}\right|<1 .
$$

It is known that each of the domain $D_{k}$ possesses a distinguished boundary [1] or characteristic manifold [2, p. 6] $C_{k}: C_{1} \equiv C_{1}(m, n)$ consists of the $(m, n)$ matrices $u$ satisfying the condition $u u^{*}=I_{0} \quad C_{2} \equiv C_{2}(n)$ consists of all symmetric unitary matrices of order $n . C_{3} \equiv C_{3}(n)$ [2, p. 71] consists of all matrices $u$ of the form $u=w^{\prime} s_{1} w$, where $w$ is an $n$-rowed unitary matrix and

$$
s_{1}= \begin{cases}\left(\begin{array}{cc}
0 & 1 \\
-1 & 0
\end{array}\right)+\cdots+\left(\begin{array}{cc}
0 & 1 \\
-1 & 0
\end{array}\right) & \text { for even } n \\
\left(\begin{array}{cc}
0 & 1 \\
-1 & 0
\end{array}\right)+\cdots+\left(\begin{array}{cc}
0 & 1 \\
-1 & 0
\end{array}\right)+0 & \text { for odd } n .\end{cases}
$$

$C_{4} \equiv C_{4}(1, n)$ consists of all $(1, n)$ matrices $u$ of the form

$$
u=e^{i \theta} x, \quad x x^{\prime}=1, \quad 0 \leqq \theta \leqq \pi
$$

Received October 9, 1964. 
where $x$ is a real vector.

We denote the Poisson kernel on $D_{k}$ by $P_{k}(z, u)$, its explicit forms [3, 4] being given in following sections. The following Dirichlet problem is solved on $D_{k}$ [2,3]: Given a real-valued continuous function $f(u)$ on $C_{k}$, the Poisson integral

$$
\phi(z)=\int_{\sigma_{k}} f(u) P_{K}(z, u) \dot{u}
$$

where $\dot{u}$ is Euclidean volume element on $C_{k}$, gives the unique function which is harmonic, in the sense given in [3], on the closure of $D_{k}$ and takes the given boundary values $f(u)$ on $C_{k}$. We obtain Harnack's inequality on each $D_{k}$ as a consequence of evaluating upper and lower bounds for $P_{k}(z, u)$.

2. Harnack's inequalities on $D_{1}$ and $D_{2}$. The Poisson kernel on $D_{1}[3,4]$ is

$$
P_{1}(z, u)=\frac{1}{V_{1}} \frac{\left[\operatorname{det}\left(I-z z^{*}\right)\right]^{n}}{\left|\operatorname{det}\left(I-z u^{*}\right)\right|^{2 n}}
$$

where $z \in D_{1}, u \in C_{1}$ and $V_{1}$ is the Euclidean volume of $C_{1}$. It is known [4, p. 411] that $P_{1}>0$ and $\int_{\sigma_{1}} P_{1} \dot{u}=1$. In [6], we obtained bounds of the Poisson kernel (5) for the case $m=n$ :

$$
\frac{1}{V_{1}} \prod_{k=1}^{n}\left(\frac{1-r_{k}}{1+r_{k}}\right)^{n} \leqq P_{1}(z, u) \leqq \frac{1}{V_{1}} \prod_{k=1}^{n}\left(\frac{1+r_{k}}{1-r_{k}}\right)^{n}
$$

where $z=u_{0} R v_{0} \in D_{1}(n, n), u \in C_{1}(n, n), u_{0}$ and $v_{0}$ are unitary matrices and $R=\left(\delta_{j_{k}} r_{k}\right)$ is a diagonal matrix with $0 \leqq r_{k}<1$ for $k=1,2, \cdots, n$. In order to obtain (6), we proved the inequality

$$
\text { ( 7) } \prod_{k=1}^{n}\left(1-r_{k}\right)^{2} \leqq\left|\operatorname{det}\left(I-z u^{*}\right)\right|^{2}=\left|\operatorname{det}\left((v-R)\left(v^{*}-R\right)\right)\right| \leqq \prod_{k=1}^{n}\left(1+r_{k}\right)^{2}
$$

where $u, \in C_{1}(n, n)$, is any unitary matrix of order $n, z \in D_{1}(n, n)$ and $v=u_{0}^{*} u v_{0}^{*}$.

For $z \in D_{1}(m, n)$ there are unitary matrices $u_{0}$ of order $m$ and $v_{0}$ of order $n$ such that $z=u_{0}(R, 0) v_{0}$, where $R$ is a diagonal submatrix $\left(\delta_{j_{k}} \boldsymbol{r}_{k}\right)$ of order $m$ and 0 is the $(m, n-m)$ zero submatrix [3, p. 1049]. Hence

$$
\operatorname{det}\left(I^{(m)}-z z^{*}\right)=\operatorname{det}\left(I^{(m)}-R R^{*}\right)=\prod_{k=1}^{m}\left(1-r_{k}^{2}\right) .
$$

For the denominator of (5) we have

$$
\operatorname{det}\left(I-z u^{*}\right)=\operatorname{det}\left(I-\left(\begin{array}{l}
z \\
0
\end{array}\right)\left(\begin{array}{l}
u \\
u_{1}
\end{array}\right)^{*}\right)
$$


where 0 is the $(n-m, n)$ zero submatrix and $u_{1}$ is chosen so that $U \equiv\left(\begin{array}{l}u \\ u_{1}\end{array}\right)$ becomes a unitary matrix of order $n[5, \mathrm{p} .190]$. If we also denote $Z \equiv\left(\begin{array}{l}z \\ 0\end{array}\right)$, then $Z \in D_{1}(n, n)$ and $U \in C_{1}(n, n)$ for the case $m=n$. Therefore from (7)

$$
\max _{U \in O_{1}}\left\{\left|\operatorname{det}\left(I-Z U^{*}\right)\right|^{2}\right\} \leqq \prod_{k=1}^{n}\left(1+r_{k}\right)^{2}=\prod_{k=1}^{m}\left(1+r_{k}\right)^{2}
$$

and

$$
\min _{\delta \in O_{1}}\left\{|\operatorname{det}(I-Z U)|^{2}\right\} \geqq \prod_{k=1}^{n}\left(1-r_{k}\right)^{2}=\prod_{k=1}^{m}\left(1-r_{k}\right)^{2}
$$

since $r_{m+1}=\cdots=r_{n}=0$ in $Z$. Finally from (9), (10) and (11) we obtain

$$
\prod_{k=1}^{m}\left(1-r_{k}\right)^{2} \leqq\left|\operatorname{det}\left(I-z u^{*}\right)\right|^{2} \leqq \prod_{k=1}^{m}\left(1+r_{k}\right)^{2}
$$

where $z=u_{0}(R, 0) v_{0} \in D_{1}(m, n)$ and $u \in C_{1}(m, n)$. This and (8) lead to

$$
\frac{1}{V_{1}} \prod_{k=1}^{m}\left(\frac{1-r_{k}}{1+r_{k}}\right)^{n} \leqq P_{1}(z, u) \leqq \frac{1}{V_{1}} \prod_{k=1}^{m}\left(\frac{1+r_{k}}{1-r_{k}}\right)^{n}
$$

for $z \in D_{1}$ and $u \in C_{1}$. Furthermore from (4) we obtain Harnack's inequality

$$
\prod_{k=1}^{m}\left(\frac{1-r_{k}}{1+r_{k}}\right)^{n} \phi(0) \leqq \phi(z) \leqq \prod_{k=1}^{m}\left(\frac{1+r_{k}}{1-r_{k}}\right)^{n} \phi(0)
$$

For $z \in D_{2}(n)$ it is known that there is a unitary matrix $u_{0}$ such that $u_{0} z u_{0}^{\prime}=\left(\delta_{j_{k}} r_{k}\right)$ where $r_{1}, \cdots, r_{n}$ are the positive square roots of the characteristic roots of $z \bar{z}$. Since $z \in D_{2}(n)$ implies $z \in D_{1}(n, n)$ and the characteristic manifold $C_{2}(n)$ is a subset of $C_{1}(n, n)$ we know that (7) and (8) hold for $z \in D_{2}(n)$ and $u \in C_{1}(n, n)$, and it can be seen from the Poisson kernel

$$
P_{2}(z, u)=\frac{1}{V_{2}} \frac{[\operatorname{det}(I-z \bar{z})]^{(n+1) / 2}}{|\operatorname{det}(I-z \bar{u})|^{n+1}}
$$

that Harnack's inequality on $D_{2}(n)$ is

$$
\prod_{k=1}^{n}\left(\frac{1-r_{k}}{1+r_{k}}\right)^{(n+1) / 2} \phi(0) \leqq \phi(z) \leqq \prod_{k=1}^{n}\left(\frac{1+r_{k}}{1-r_{k}}\right)^{(n+1) / 2} \phi(0) .
$$

3. Harnack's inequality on $D_{3}$. The Poisson kernel on $D_{3}$ is

$$
P_{3}(z, u)=\frac{1}{V_{3}} \frac{\left[\operatorname{det}\left(I-z z^{*}\right)\right]^{a}}{\left|\operatorname{det}\left(I-z u^{*}\right)\right|^{2 a}}
$$


where $a=(n-1) / 2$ for even $n$ and $a=n / 2$ for odd $n$. For $z \in D_{3}(n)$ ! it is known [2, p. 67] that there is a unitary matrix $u_{0}$ such that

$$
u_{0} z u_{0}^{\prime}=s=\left\{\begin{array}{l}
\left(\begin{array}{cc}
0 & r_{1} \\
-r_{1} & 0
\end{array}\right)+\left(\begin{array}{cc}
0 & r_{2} \\
-r_{2} & 0
\end{array}\right)+\cdots+\left(\begin{array}{cc}
0 & r_{b} \\
-r_{b} & 0
\end{array}\right) \quad \text { for even } n \\
\left(\begin{array}{cc}
0 & r_{1} \\
-r_{1} & 0
\end{array}\right)+\left(\begin{array}{cc}
0 & r_{2} \\
-r_{2} & 0
\end{array}\right)+\cdots+\left(\begin{array}{cc}
0 & r_{[b]} \\
-r_{[b]} & 0
\end{array}\right)+0 \text { for odd } n
\end{array}\right.
$$

where $b=n / 2$ and $r_{2}^{1}, r_{2}^{2}, \cdots$ are characteristic roots of $z z^{*}$. Thus for even $n$

$$
u_{0} z z^{*} u_{0}^{*}=\left[r_{1}^{2}, r_{1}^{2}, \cdots, r_{b}^{2}, r_{b}^{2}\right]
$$

And for all $n$

$$
\operatorname{det}\left(I-z z^{*}\right)=\operatorname{det}\left(I-u_{0} z z^{*} u_{0}^{*}\right)=\prod_{k=1}^{[b]}\left(1-r_{k}^{2}\right)^{2} .
$$

We denote the right hand side of (2) by $u_{1}$ with the change that the last term 0 be replaced by 1 in the case of odd $n$. Hence $u_{1}$ is a unitary matrix of order $n$ and from (13) $s u_{1}^{*}$ is a diagonal matrix $R \equiv\left[r_{1}, r_{1}, \cdots, r_{[b]}, r_{[b]}\right]$ for even $n$ and $R_{0} \equiv[R, 0]$ for odd $n$. First we consider the case of even $n$. We notice from (2) that $u \in C_{3}$ is skew-symmetric unitary. Therefore for $z \in D_{3}$ and $u \in C_{3}$

$$
\left|\operatorname{det}\left(I-z u^{*}\right)\right|=\left|\operatorname{det}\left(I-u_{0}^{*} s u_{1}^{*} u_{1} \bar{u}_{0} u^{*}\right)\right|=|\operatorname{det}(v-R)|
$$

where $v=u_{0} u u_{0}^{\prime} u_{1}^{*}$ is a unitary matrix of order $n$. Hence from (7) we have

$$
\prod_{k=1}^{b}\left(1-r_{k}\right)^{2} \leqq\left|\operatorname{det}\left(I-z u^{*}\right)\right| \leqq \prod_{k=1}^{b}\left(1+r_{k}\right)^{2} .
$$

For the case of odd $n$, we notice from (2) that $\operatorname{det}(u)=0$. It is known [3, p. 1073] that any $v \in C_{3}(n+1)$ can be written in the form

$$
v=\left(\begin{array}{cc}
u & w^{\prime} h^{\prime} \\
-h w & 0
\end{array}\right), \quad h=\left(0, \cdots, 0, e^{i \theta}\right)
$$

where $u=w^{\prime} s_{1} w \in C_{3}(n)$. Hence for odd $n$

$$
\operatorname{det}\left(I-z u^{*}\right)=\operatorname{det}\left(I^{(n+1)}-\left(\begin{array}{cc}
z & 0 \\
0 & 0
\end{array}\right)\left(\begin{array}{cc}
u & w^{\prime} h^{\prime} \\
-h w & 0
\end{array}\right)^{*}\right)
$$

and from (13)

$$
\left(\begin{array}{cc}
u_{0} & 0 \\
0 & 1
\end{array}\right)\left(\begin{array}{cc}
z & 0 \\
0 & 0
\end{array}\right)\left(\begin{array}{cc}
u_{0} & 0 \\
0 & 1
\end{array}\right)^{\prime}=R+\left(\begin{array}{ll}
0 & 0 \\
0 & 0
\end{array}\right) .
$$

Since $n+1$ is even we can apply (14) and obtain 


$$
\prod_{k=1}^{[b]}\left(1-r_{k}\right)^{2} \leqq\left|\operatorname{det}\left(I-z u^{*}\right)\right| \leqq \prod_{k=1}^{[b]}\left(1+r_{k}\right)^{2} .
$$

As the result, this inequality is good for both odd and even $n$. Thus, as in $\S 2$ we can obtain both bounds for the Poisson kernel $P_{3}(z, u)$ and finally Harnack's inequality on $D_{3}(n)$ as

$$
\prod_{k=1}^{[b]}\left(\frac{1-r_{k}}{1+r_{k}}\right)^{2 a} \phi(0) \leqq \phi(z) \leqq \prod_{k=1}^{[b]}\left(\frac{1+r_{k}}{1-r_{k}}\right)^{2 a} \phi(0)
$$

where $b=n / 2$ and $a=(n-1) / 2$ for even $n$ and $a=n / 2$ for odd $n$.

4. Harnack's inequality on $D_{4}$. The Poisson kernel on $D_{4}$ is

$$
P_{4}(z, u)=\frac{1}{V_{4}} \frac{\left(1+\left|z z^{\prime}\right|^{2}-2 z z^{*}\right)^{n / 2}}{\left|1+z z^{\prime} u u^{\prime}-2 z u^{*}\right|^{n}}
$$

where $z \in D_{4}$ and $u \in C_{4}$. For every fixed $z \in D_{4}$ there is a real orthogonal matrix $t$ such that [3, p. 1037]

$$
z=\left(z_{1}, z_{2}, 0, \cdots, 0\right) t \text {. }
$$

Thus we have

$$
1+\left|z z^{\prime}\right|^{2}-2 z z^{*}=1+\left|z_{1}^{2}+z_{2}^{2}\right|^{2}-2\left(\left|z_{1}\right|^{2}+\left|z_{2}\right|^{2}\right) .
$$

Here by denoting $\quad z_{1}-i z_{2} \equiv w_{1}=r_{1} e^{i \theta_{1}} \quad$ and $\quad z_{1}+i z_{2} \equiv w_{2}=r_{2} e^{i \theta_{2}}$, from (1)

(16) $0<1+\left|z z^{\prime}\right|^{2}-2 z z^{*}=\left(1-\left|w_{1}\right|^{2}\right)\left(1-\left|w_{2}\right|^{2}\right)=\left(1-r_{1}^{2}\right)\left(1-r_{2}^{2}\right)$

and

$$
0<1-\left|z z^{\prime}\right|=1-\left|z_{1}^{2}+z_{2}^{2}\right|=1-\left|w_{1} w_{2}\right|=1-r_{1} r_{2},
$$

hence

$$
0 \leqq r_{k}<1,
$$$$
k=1,2 .
$$

Next, from $z \in D_{4}$ in (15) and $u \in C_{4}$ in (3)

$$
z z^{\prime} \overline{u u^{\prime}}=\left(z_{1}^{2}+z_{2}^{2}\right) e^{-2 i \theta}=w_{1} w_{2} e^{-2 i \theta}
$$

and

$$
2 z u^{*}=2\left(z_{1}, z_{2}, 0, \cdots, 0\right) t x^{\prime} e^{-i \theta} .
$$

By denoting $t=\left(t_{j_{k}}\right)$ we have $t x^{\prime}=\left(a_{1}, a_{2}, \cdots, a_{n}\right)^{\prime}$ where $a_{j}=\sum_{k=1}^{n} t_{j_{k}} x_{k}$ and since

$$
\sum_{j=1}^{n} a_{j}^{2}=\left(t x^{\prime}\right)^{\prime}\left(t x^{\prime}\right)=x t^{\prime} t x^{\prime}=x x^{\prime}=1
$$


we have $a_{1}^{2}+a_{2}^{2} \leqq 1$. Now with $z_{1}=\left(w_{1}+w_{2}\right) / 2$ and $z_{2}=i\left(w_{1}-w_{2}\right) / 2$, we have $2 z u^{*}=\left(a w_{1}+\bar{a} w_{2}\right) e^{-i \theta}$ where $a=a_{1}+i a_{2}$ and $|a|^{2} \leqq 1$. Thus

$$
1+z z^{\prime} \overline{u u^{\prime}}-2 z u^{*}=1+w_{1} w_{2} e^{-2 i \theta}-\left(a w_{1}+\bar{a} w_{2}\right) e^{-i \theta} .
$$

We wish to find upper and lower bounds for the absolute values of expression (17). We consider the image of the closed unit disk $|a| \leqq 1$ under the mapping $f(a)=\alpha w_{1}+\bar{a} w_{2}$ for $a=r e^{i \alpha}$. Here $f(a)$ can be written in the form

$$
f(\alpha)=r\left[r_{1}\left(e^{i \beta}+e^{-i \beta}\right)+\left(r_{2}-r_{1}\right) e^{-i \beta}\right] e^{i\left(\theta_{1}+\theta_{2}\right) / 2}
$$

where $\beta=\alpha+\left(\theta_{1}-\theta_{2}\right) / 2$. For the case $r_{1}=r_{2}, f(a)$ maps the closed unit disk onto a line segment of length $4 r_{1}$. When $r_{1} \neq r_{2}$, the image is a simple closed connected region. Furthermore the image of the unit circle is the line segment when $r_{1}=r_{2}$ and is the boundary of the region when $r_{1} \neq r_{2}$. Hence from the fact that $1+z z^{\prime} \overline{u u^{\prime}}-2 z u^{*} \neq 0$ $[3$, p. 1079] we know that the maximum and the minimum of the $a b-$ solute values of (17) can be found in the case $|a|=1$. Thus

$$
1+w_{1} w_{2} e^{-2 i \theta}-\left(\alpha w_{1}+\bar{a} w_{2}\right) e^{-i \theta}=\left(1-\alpha w_{1} e^{-i \theta}\right)\left(1-\bar{a} w_{2} e^{-i \theta}\right)
$$

and therefore

$$
\left(1-r_{1}\right)\left(1-r_{2}\right) \leqq\left|1+z z^{\prime} \overline{u u^{\prime}}-2 z u^{*}\right| \leqq\left(1+r_{1}\right)\left(1+r_{2}\right) .
$$

This and (16) give us

$$
\frac{1}{V_{4}} \prod_{k=1}^{2}\left(\frac{1-r_{k}}{1+r_{k}}\right)^{n / 2} \leqq P_{4}(z, u) \leqq \frac{1}{V_{4}} \prod_{k=1}^{2}\left(\frac{1+r_{k}}{1-r_{k}}\right)^{n / 2}
$$

and the corresponding Harnack's inequality

$$
\prod_{k=1}^{2}\left(\frac{1-r_{k}}{1+r_{k}}\right)^{n / 2} \phi(0) \leqq \phi(z) \leqq \prod_{k=1}^{2}\left(\frac{1+r_{k}}{1+r_{k}}\right)^{n / 2} \phi(0) .
$$

\section{REFERENCES}

1. S. Bergman, The kernel function and conformal mapping, Amer. Math. Soc. New York, 1950.

2. L. K. Hua, Harmonic analysis of functions of several complex variables in the classical domains, Amer. Math. Soc. Rhode Island, 1963.

3. L. K. Hua and K. H. Look, Theory of harmonic functions in classical domains, Sci. Sinica 8 (1959), 1031-1094.

4. J. Mitchell, Potential theory in the geometry of matrices, Trans. Amer. Math. Soc. 79 (1955), 401-422.

5. S. Perlis, Theory of matrices, Addison-Wesley, Cambridge, 1952.

6. S. H. Tung, Harnack's inequality and theorems on matrix spaces, Proc. Amer. Math. Soc. 15 (1964), 375-381.

MIAMI UNIVERSITY, OXFORD, OHIO 


\section{PACIFIC JOURNAL OF MATHEMATICS}

\section{EDITORS}

\section{H. SAMELSON}

Stanford University

Stanford, California

\section{R. M. BLUMenthaL \\ University of Washington \\ Seattle, Washington 98105}

*J. DugundjI

University of Southern California Los Angeles, California 90007

\section{RICHARD ARENS}

University of California

Los Angeles, California 90024

\section{ASSOCIATE EDITORS}
E. F. BECKENBACH
B. H. NeUManN
F. WOLF
K. YosIDA

\section{SUPPORTING INSTITUTIONS}

\author{
UNIVERSITY OF BRITISH COLUMBIA \\ CALIFORNIA INSTITUTE OF TECHNOLOGY \\ UNIVERSITY OF CALIFORNIA \\ MONTANA STATE UNIVERSITY \\ UNIVERSITY OF NEVADA \\ NEW MEXICO STATE UNIVERSITY \\ OREGON STATE UNIVERSITY \\ UNIVERSITY OF OREGON \\ OSAKA UNIVERSITY \\ UNIVERSITY OF SOUTHERN CALIFORNIA
}

\author{
STANFORD UNIVERSITY \\ UNIVERSITY OF TOKYO \\ UNIVERSITY OF UTAH \\ WASHINGTON STATE UNIVERSITY \\ UNIVERSITY OF WASHINGTON \\ AMERICAN MATHEMATICAL SOCIETY \\ CHEVRON RESEARCH CORPORATION \\ TRW SYSTEMS \\ NAVAL ORDNANCE TEST STATION
}

Mathematical papers intended for publication in the Pacific Journal of Mathematics should be typewritten (double spaced). The first paragraph or two must be capable of being used separately as a synopsis of the entire paper. It should not contain references to the bibliography. Manuscripts may be sent to any one of the four editors. All other communications to the editors should be addressed to the managing editor, Richard Arens at the University of California, Los Angeles, California 90024.

50 reprints per author of each article are furnished free of charge; additional copies may be obtained at cost in multiples of 50 .

The Pacific Journal of Mathematics is published monthly. Effective with Volume 16 the price per volume (3 numbers) is $\$ 8.00$; single issues, $\$ 3.00$. Special price for current issues to individual faculty members of supporting institutions and to individual members of the American Mathematical Society: $\$ 4.00$ per volume; single issues $\$ 1.50$. Back numbers are available.

Subscriptions, orders for back numbers, and changes of address should be sent to Pacific Journal of Mathematics, 103 Highland Boulevard, Berkeley 8, California.

Printed at Kokusai Bunken Insatsusha (International Academic Printing Co., Ltd.), No. 6, 2-chome, Fujimi-cho, Chiyoda-ku, Tokyo, Japan.

PUBLISHED BY PACIFIC JOURNAL OF MATHEMATICS, A NON-PROFIT CORPORATION

The Supporting Institutions listed above contribute to the cost of publication of this Journal, but they are not owners or publishers and have no responsibility for its content or policies.

* Paul A. White, Acting Editor until J. Dugundji returns. 


\section{Pacific Journal of Mathematics}

\section{Vol. 16, No. 2 December, 1966}

Loren N. Argabright, Invariant means on topological semigroups ........ 193

William Arveson, A theorem on the action of abelian unitary groups ...... 205

John Spurgeon Bradley, Adjoint quasi-differential operators of Euler

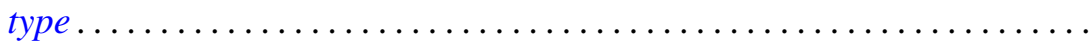

Don Deckard and Lincoln Kearney Durst, Unique factorization in power series rings and semigroups ........................... 239

Allen Devinatz, The deficiency index of ordinary self-adjoint differential operators..................................... 243

Robert E. Edwards, Operators commuting with translations ............ 259

Avner Friedman, Differentiability of solutions of ordinary differential equations in Hilbert space .............................. 267

Boris Garfinkel and Gregory Thomas McAllister, Jr., Singularities in a variational problem with an inequality ......................

Seymour Ginsburg and Edwin Spanier, Semigroups, Presburger formulas,

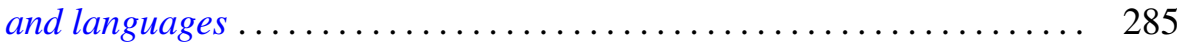

Burrell Washington Helton, Integral equations and product integrals . . . . . . 297

Edgar J. Howard, First and second category Abelian groups with the n-adic topology.........................................

Arthur H. Kruse and Paul William Liebnitz, Jr., An application of a family homotopy extension theorem to ANR spaces.

Albert Marden, I. Richards and Burton Rodin, On the regions bounded by homotopic curves

Willard Miller, Jr., A branching law for the symplectic groups ...

Marc Aristide Rieffel, A characterization of the group algebras of the finite

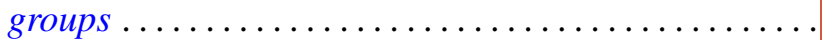

P. P. Saworotnow, On two-sided $H^{*}$-algebras

John Griggs Thompson, Factorizations of p-solvable groups ...

Shih-hsiung Tung, Harnack's inequalities on the classical Cartan

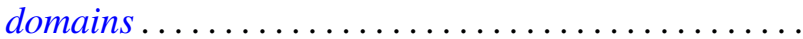

